\title{
Current status of research on osteoporosis in COPD: a systematic review
}

\author{
L. Graat-Verboom*,\#, E.F.M. Wouters",I, F.W.J.M. Smeenk*, \\ B.E.E.M. van den Borne*, R. Lunde ${ }^{+}$and M.A. Spruit
}

ABSTRACT: Patients with chronic obstructive pulmonary disease (COPD) are at increased risk of osteoporosis. However, the prevalence, correlates and effectiveness of treatment of osteoporosis in COPD patients remain unclear.

We performed a systematic review of the literature to answer three questions. 1) What is the prevalence of osteoporosis in COPD? 2) What are identified correlates of osteoporosis in COPD? 3) What are the effects of treatment of osteoporosis in COPD? A computerised literature search in MEDLINE/PubMed and the Cochrane database was carried out. In addition, reference lists were searched by hand and authors were contacted if necessary.

The prevalence of osteoporosis and osteopenia varied 9-69\% and 27-67\%, respectively. Prevalence of osteoporosis was generally higher than in healthy subjects and some other chronic lung diseases. Correlates of osteoporosis in COPD are mainly measures of body composition, disease severity and the use of corticosteroids, although causality has not been proven. Effects of treatment of osteoporosis have not been investigated in samples consisting of COPD patients only.

Longitudinal follow-up to assess determinants of osteoporosis in COPD and randomised placebo-controlled trials on the effects of treatment of osteoporosis in patients with COPD only are warranted.

KEYWORDS: Bone loss, bone mineral density, chronic obstructive pulmonary disease, pharmacotherapy, systemic effects

hronic obstructive pulmonary disease (COPD) is characterised by a progressive airflow limitation that is not fully reversible and is associated with an abnormal inflammatory response of the lung to noxious particles and gases [1]. The degree of airflow limitation can be assessed by spirometry and stratified in accordance with the Global Initiative for Chronic Obstructive Pulmonary Disease (GOLD) [1]. Although primarily a pulmonary disease, there are significant extrapulmonary effects in COPD [2-5]. Indeed, the GOLD guidelines incorporated these extrapulmonary effects in their definition of COPD [1]. Examples of extrapulmonary effects are increased arterial stiffness [3], skeletal muscle atrophy [4], systemic hypertension [6] and osteoporosis [7].

Osteoporosis is a systemic skeletal disease characterised by a low bone mass and/or microarchitectural deterioration of bone tissue leading to increased bone fragility and increased fracture risk [8]. Known risk factors for osteoporosis in the general population are, among others, female sex, advanced age, low body weight, chronic glucocorticoid therapy and endocrinological disorders such as hyperthyroidism and primary hyperparathyroidism [8-11]. In COPD, the prevalence of osteoporosis is assumed to be two- to five-fold higher than in age-matched subjects without airflow obstruction [3, 12]. Indeed, in a recently developed screening tool for males at risk for osteoporosis, the presence of COPD is one of the parameters increasing this risk almost four times [13].

The burden of osteoporosis varies with the incidence of fracture risk [8]. Fractures of the hip, vertebrae and forearm are the most common fractures in patients with osteoporosis, although fractures of other body parts can also be the result
AFFILIATIONS

*Dept of Respiratory Medicine, Catharina Hospital Eindhoven, Eindhoven,

\#Dept of Respiratory Medicine, Maastricht University Medical Centre, Maastricht,

'Dept of Research, Development \& Education, Centre for Integrated Rehabilitation of Organ failure (CIRO), Horn, and ${ }^{+}$Dept of Respiratory Medicine, St Jans Gasthuis, Weert, The Netherlands.

CORRESPONDENCE

L. Graat-Verboom

Dept of Respiratory Medicine

Maastricht University Medical Centre

P. Debyelaan 25

6229 HX Maastricht

The Netherlands

E-mail: lidwiengraat@versatel.nl

Received:

Aug 242008

Accepted after revision:

Dec 222008 
of osteoporosis [8]. The treatment of osteoporosis aims at fracture prevention and, according to the World Health Organization (WHO), should consist of lifestyle modification (such as smoking cessation, weight-bearing physical exercise and adequate calcium intake) and drug treatment [8]. The latter should consist of bisphosphonates, calcium supplementation (in the case of low dietary intake) and vitamin D supplementation (in the case of vitamin D deficiency). Especially in COPD patients it is important to prevent vertebral fractures since they might result in a decreased forced vital capacity [14]. In addition, (osteoporotic) hip fractures in COPD patients pose a greater problem than hip fractures in otherwise healthy subjects because of the increased operative risk in COPD patients [15-17].

The aim of this article was to perform a systematic review of the literature in order to answer the following questions. 1) What is the prevalence of osteoporosis in COPD? 2) What are identified correlates of osteoporosis in COPD? 3) What are the effects of treatment of osteoporosis in COPD?

\section{METHODS}

A computerised literature search of the MEDLINE/PubMed and the Cochrane databases was performed. The time span was January 1988 to April 2008. For each question two groups of keywords were used to search for relevant articles.

To determine the prevalence of osteoporosis in COPD the keywords were: 1) COPD, chronic obstructive pulmonary disease, emphysema, chronic bronchitis; 2) osteoporosis, osteopenia, dual-energy X-ray absorptiometry (DXA) scan, bone mineral density, prevalence of osteoporosis, prevalence of osteopenia.

To identify correlates of osteoporosis in COPD the keywords were: 1) COPD, chronic obstructive pulmonary disease, emphysema, chronic bronchitis; 2) osteoporosis, osteopenia, risk factors for osteoporosis, determining factors for osteoporosis, screening for osteoporosis.

Finally, to determine the effects of treatment of osteoporosis in COPD the keywords were: 1) COPD, chronic obstructive pulmonary disease, emphysema, chronic bronchitis; 2) treatment of osteoporosis, lifestyle interventions in osteoporosis, bisphosphonates, calcium supplementation, vitamin D.

For each of the three searches, keywords from group 1 were combined with the keywords from group 2 by "AND". Within each group, the keywords were combined using "OR". In addition, reference lists of the identified articles were searched by hand in order to find relevant articles that were missed in the initial search strategy.

\section{Article selection}

Non-English articles were excluded. In addition, we excluded review articles, although we did search their reference lists by hand for relevant articles. Finally, editorials, congress abstracts and case reports were not included.

\section{Prevalence of osteoporosis in COPD}

Only studies that enrolled COPD patients or where COPD patients could be isolated from the studied sample (in the case of inclusion of patients with other diseases besides COPD) were included. One of the outcomes had to be the prevalence of osteoporosis based on bone mineral density (BMD) measurements, thereby excluding studies with a prevalence of osteoporosis based on (osteoporotic) fractures. Moreover, a definition of osteoporosis had to be given by the authors. Cross-sectional, longitudinal and intervention trials were included. When the prevalence of osteoporosis was given per site only (e.g. hip or lumbar spine), we contacted the authors by $\mathrm{e}$-mail to ask for the prevalence of the combined sites (i.e. if one of the sites was diagnosed as osteoporosis then the patient was defined as having osteoporosis). We determined the overall mean prevalence of osteoporosis in 13 identified studies (see online supplementary material).

\section{Correlates of osteoporosis in COPD}

Only studies investigating correlates of osteoporosis in COPD patients, or where COPD patients could be isolated from studied samples (in the case of inclusion of patients with other diseases besides COPD) were included. Correlation and/or regression analysis had to be carried out by searching for clinical outcomes associated with osteoporosis or BMD (thereby excluding studies with fractures as primary endpoints). Cross-sectional, longitudinal and intervention trials were included.

\section{Treatment of osteoporosis in COPD}

Again, only studies where the results for COPD patients could be isolated from other groups of patients were included. In addition, only randomised placebo-controlled trials studying the effects of lifestyle interventions (e.g. more weight-bearing exercise, smoking cessation) and/or "osteoporosis medication" (e.g. bisphosphonates, calcium supplementation, vitamin D) were included.

To assess the methodological quality of identified trials, the Delphi list was used [18]. The Delphi list is a comprehensive criteria list for quality assessment of randomised controlled trials (RCTs) for conducting systematic reviews. It consists of nine items all having a "yes", "no" or "don't know" answer. If bias was unlikely, the criterion was rated positive ("yes"). In cases where information was lacking or insufficient and/or if bias was likely, the criterion was rated negative ("no" or "don't know", respectively). All "yes" scores (1 point per "yes") were summed to produce an overall quality score.

\section{RESULTS}

\section{Prevalence of osteoporosis in COPD}

The search resulted in 240 articles. Of these 42 articles were not in the English language, 48 were review articles and six were editorials or letters. Another 94 articles were excluded because they were about other topics (clear from the abstracts only). After reading the remaining articles, another 36 were excluded: 12 because COPD patients could not be isolated from other groups under investigation and 24 because they were about other topics. One article was excluded because a subgroup of patients used in a previous paper was investigated (see online supplement). Finally, 13 studies with a total of 775 COPD patients were included. In total, there were more male patients $(67 \%$ versus $33 \%, n=759)$. Moreover, patients had a mean \pm SD age (if reported) of $63.4 \pm 5.2 \mathrm{yrs}(\mathrm{n}=775)$, a forced expiratory volume in $1 \mathrm{~s}$ (FEV1) of $46.7 \pm 13.5 \%$ predicted $(\mathrm{n}=514)$, a body mass index (BMI) of $24.9 \pm 2.3 \mathrm{~kg} \cdot \mathrm{m}^{-2}(\mathrm{n}=721)$ and a 
fat-free mass index (FFMI) of $16.7 \pm 0.9 \mathrm{~kg} \cdot \mathrm{m}^{-2} \quad(\mathrm{n}=311)$ (table 1).

The prevalence of osteoporosis varies from $9 \%$ to $69 \%$ depending on the patients under study, the method used to assess BMD and the definition used to define osteoporosis (table 1). The overall mean prevalence of osteoporosis for the 13 identified studies was $35.1 \%$ (272 of 775 patients). Patients with osteoporosis consisted of a higher proportion of women. In addition, FEV1 (\% pred), BMI and FFMI were lower in the osteoporotic COPD patients (table 2).

Univariate binary logistic regression analysis showed that females had an odds ratio (OR) of 1.968 for osteoporosis $(p<0.001)$. A lower FEV1, BMI and FFMI increased the OR of osteoporosis, while age had no significant influence on osteoporosis in COPD (see online supplementary material, table E1).

Eight studies determined the prevalence of osteopenia, which varies $27-67 \%$, resulting in an overall mean prevalence of osteopenia of $38.4 \%$ in COPD (table 1 ).

Four studies included an age-matched control group of healthy subjects $[3,12,23,27]$. The prevalence of osteoporosis in COPD was increased compared with the healthy subjects in three trials (overall mean prevalence of osteoporosis of $31.7 \%$ in COPD versus $5.8 \%$ in healthy subjects, $\mathrm{p}<0.001)[3,12$, 27]. However, KARADAG et al. [23] did not find a significant difference in prevalence of osteoporosis between COPD patients and healthy subjects (fig. 1). Nevertheless, the significant difference in the prevalence of osteoporosis between COPD patients and healthy subjects still remained after analyses of the four trials together: 32.5 versus $11.4 \%$, respectively, $\mathrm{p}<0.001$.

Four studies included a control group of patients with other chronic lung diseases [19, 25, 26, 29]. The prevalence of osteoporosis was higher in patients with COPD than in patients with: asthma (50\% versus $21 \%$, respectively) [25]; idiopathic pulmonary fibrosis (69\% versus $43 \%$, respectively) [26]; pulmonary hypertension (69\% versus 55\%, respectively) [26]; a mixed group of idiopathic pulmonary fibrosis, pulmonary hypertension, sarcoidosis, scleroderma or Kartagener's syndrome (45\% versus 15\%, respectively) [29]; and a mixed group of $\alpha-1$ antitrypsin deficiency, sarcoidosis, lymphangioleiomyomatosis, fibrosing alveolitis and bronchiectasis (59\% versus 32\%, respectively) (fig. 2) [19]. In addition, the prevalence of osteoporosis was lower in patients with COPD than in patients with cystic fibrosis in two studies: $69 \%$ versus $76 \%$, respectively [26]; and $45 \%$ versus $75 \%$, respectively (fig. 2) [29].

\section{Correlates of osteoporosis in COPD}

In total, 207 articles were found. Of these, 43 were not in the English language, 45 were review articles and three were editorials, comments or letters. In addition, eight articles were excluded because COPD could not be isolated from other patient groups, 92 because they were not about the topic and another four based on their statistical methods (no correlation and/or regression analysis performed). Twelve studies were included for this review.

Correlates of osteoporosis and/or (a low) BMD in COPD identified in mainly cross-sectional studies were body composition measures $[12,20,22,24,25,28,30,31]$, measures of disease severity $[20,27,31,34]$ and corticosteroids [24, 31] (table 3$)$. In addition, two longitudinal studies investigating change in BMD were identified (table 3). SCANLON et al. [33] found inhaled corticosteroids to be a risk factor for decreasing BMD at both femoral neck and lumbar spine. In addition, they found an age of $>56$ yrs to be a predictor for decreasing BMD at the femoral neck, while $>65$ yrs of age and female sex to be predictors for decreasing BMD at the lumbar spine (table 3). MiNEO et al. [22] investigated COPD patients before and after lung volume reduction surgery and found significant correlations between the increase in lumbar BMD and the changes in the following parameters: residual volume (RV), diffusing capacity of the lung for carbon monoxide (DL,CO), BMI, fat-free mass (FFM), bone alkaline phosphatase (bone-AF), $\beta$-crosslaps, methylprednisolone (table 3).

\section{Treatment of osteoporosis in COPD}

The search resulted in 136 articles, 27 were excluded because they were not in the English language, 34 because they were reviews, three were editorials, letters or comments and 69 because they were about another topic. No studies were identified investigating the treatment of osteoporosis in COPD patients alone.

\section{DISCUSSION}

The prevalence of osteoporosis in COPD patients varies $9-69 \%$. In addition, the prevalence of osteopenia varies $27-67 \%$. The prevalence of osteoporosis was higher in COPD patients than in healthy subjects. Identified correlates of osteoporosis or a low BMD in COPD patients are body composition measures, disease severity and treatment with corticosteroids. Treatment of osteoporosis has not been investigated in random samples consisting of only patients with COPD.

\section{Prevalence of osteoporosis in COPD}

VRIEZE et al. [20] found a low prevalence of osteoporosis compared with the other studies (table 1). This may, at least in part, be because none of the GOLD stage II patients had osteoporosis. In contrast, BOLTON et al. [12] found a prevalence of osteoporosis in $20 \%$ of GOLD stage II patients. A possible explanation for these conflicting results could be the use of quantitative ultrasound by VRIEZE et al. [20] instead of DXA scan, which is the gold standard to assess osteoporosis [8]. The highest prevalence (69\%) of osteoporosis in COPD was reported by TsCHOPP et al. [26]. In two other studies conducted in COPD patients considered for lung transplantation, the prevalence of osteoporosis was lower $(48 \%$ and 59\%) $[19,29]$. This difference in prevalence may be due to differences in patient characteristics. However, in the absence of clinical characteristics for COPD patients only, this was hard to check [26]. Three other studies [22, 25, 28] found a relatively high prevalence of osteoporosis in COPD $(50 \%, 49 \%$ and $60 \%$, respectively). However, the mean age of these patients was 72 , 70 and 71 yrs, respectively, whereas in other studies the mean age was $\leqslant 67$ yrs (table 1 ). In addition, KATSURA and KIDA [25] defined osteoporosis according to the Japanese guidelines whereas most other studies used the WHO criteria to define osteoporosis (table 1).

We found differences in sex distribution, FEV1, BMI and FFMI after stratification for presence/absence of osteoporosis. In addition, in a logistic regression analysis we identified male 


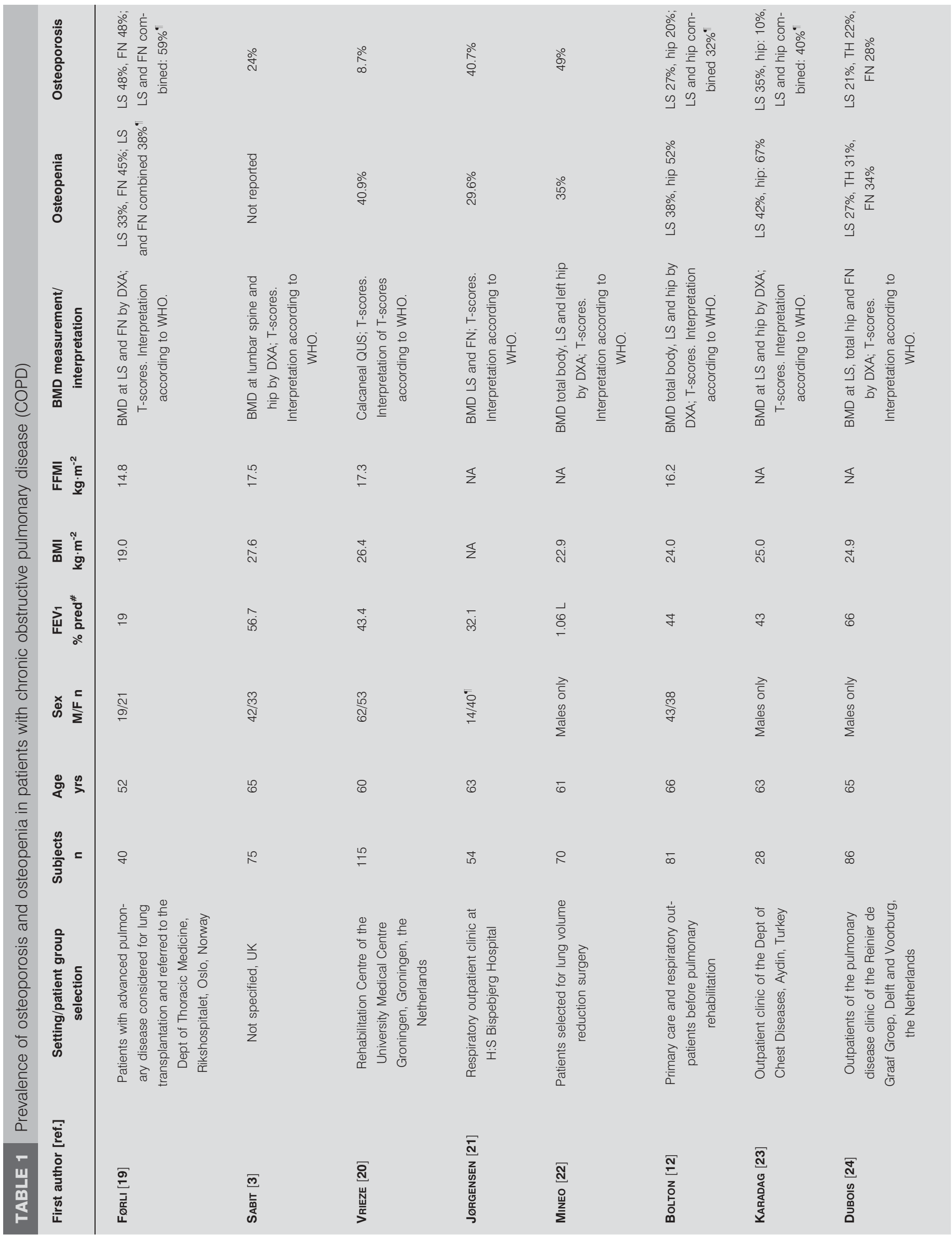




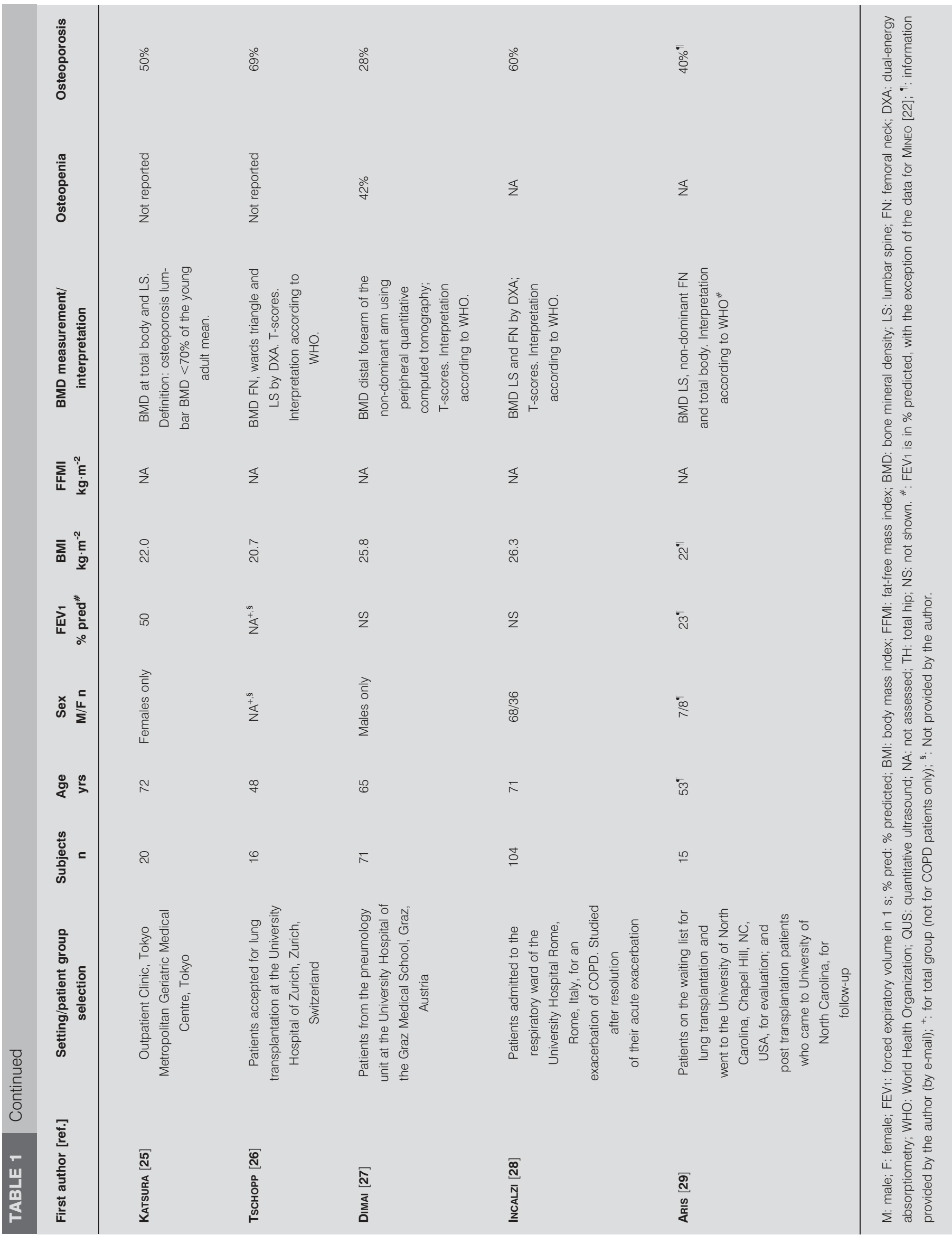




\begin{tabular}{|c|c|c|c|}
\hline \multirow[t]{2}{*}{ TABLE 2} & \multicolumn{3}{|c|}{$\begin{array}{l}\text { No osteoporosis versus osteoporosis in patients } \\
\text { with chronic obstructive pulmonary disease }\end{array}$} \\
\hline & No osteoporosis & Osteoporosis & $p$-value \\
\hline Age yrs & $63.4 \pm 4.1$ (503) & $63.4 \pm 6.7$ (272) & 0.917 \\
\hline Sex $M / F \%(n)$ & 77/23 (336) & 63/37 (233) & $<0.001^{\star \star}$ \\
\hline FEV $1 \%$ pred & $47.5 \pm 12.0(369)$ & $41.1 \pm 15.8(145)$ & $<0.001^{* *}$ \\
\hline $\mathrm{BMI} \mathbf{k g} \cdot \mathrm{m}^{-2}$ & $25.5 \pm 2.1(471)$ & $23.7 \pm 2.3(250)$ & $<0.001^{* *}$ \\
\hline $\mathrm{FFMI} \mathbf{k g} \cdot \mathrm{m}^{-2}$ & $16.9 \pm 0.7(235)$ & $16.2 \pm 1.1(76)$ & $<0.001^{\star \star}$ \\
\hline
\end{tabular}

sex, decreasing FEV1, BMI and FFMI as possible determinants of osteoporosis in COPD. Nevertheless, heterogeneity of the study designs makes it somewhat difficult to draw strong conclusions from these analyses.

On average, the prevalence of osteoporosis and/or a low BMD was significantly higher in COPD patients than in healthy subjects (fig. 1). Only one study did not find a significant difference in prevalence of osteoporosis in Turkish COPD outpatients (40\% for lumbar spine and hip combined, 35\% and $10 \%$ for lumbar spine and hip respectively) compared with their healthy peers ( $40 \%$ at lumbar spine and $15 \%$ at the hip) [23]. Nevertheless, the prevalence of osteoporosis in the healthy group appears to be higher than the prevalence of osteoporosis in healthy subjects in other studies $(0-25 \%)$ [3, 12, 27, 35].

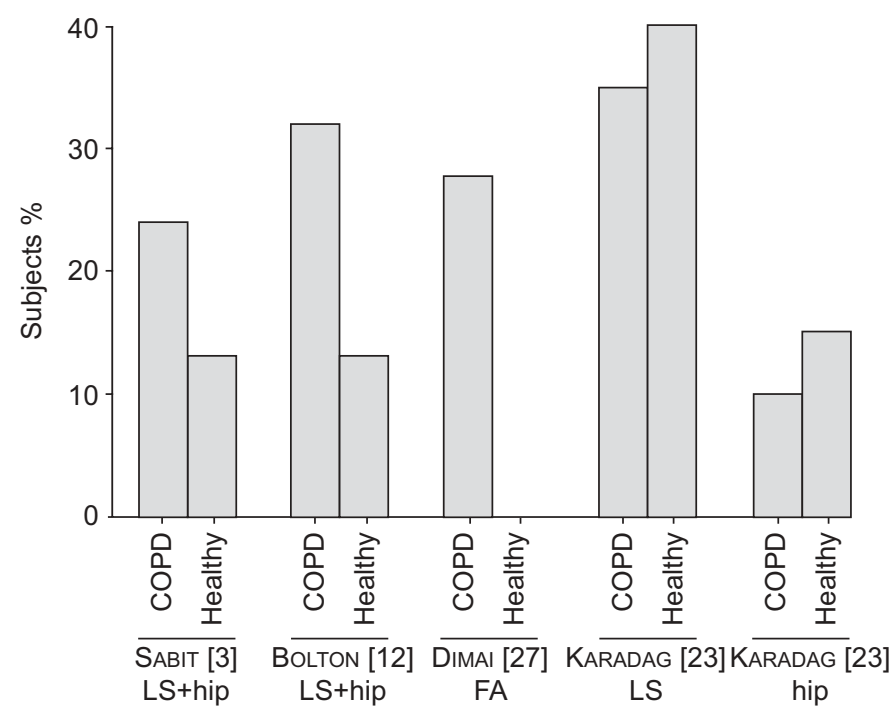

FIGURE 1. Prevalence of osteoporosis in patients with chronic obstructive pulmonary disease (COPD) versus healthy subjects. Absolute numbers included in the studies: SABIT [3] $n=75$ COPD patients, $n=42$ healthy subjects; BoLton [12] $n=81$ COPD patients, $n=38$ healthy subjects; DIMAl [27] $n=71$ COPD patients, $n=40$ healthy subjects; KARADAG [23] $n=28$ COPD patients, $n=20$ healthy subjects. For KARADAG et al. [23] prevalence for lumbar spine (LS) and hip are displayed separately (the author provided us with the combined prevalence of osteoporosis in the COPD patients (40\%); however, this combined prevalence in the healthy subjects was not provided). FA: forearm.

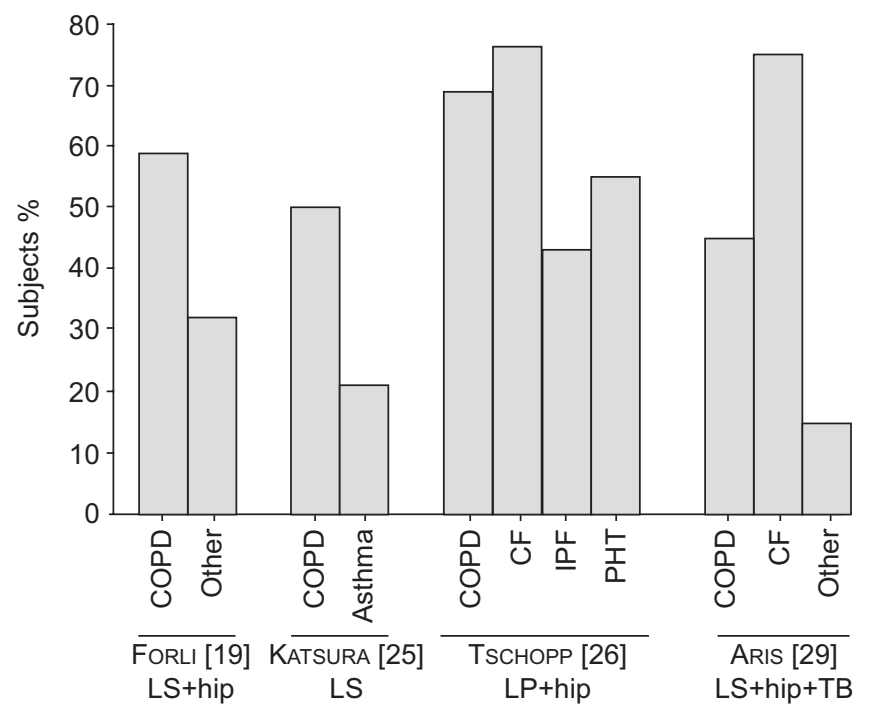

FIGURE 2. Prevalence of osteoporosis in chronic obstructive pulmonary disease (COPD) versus other respiratory disorders. Absolute numbers of patients included: FORLI [19] $n=40$ COPD patients, $n=31$ other; KATSURA [25] $n=20$ COPD patients, $n=24$ asthma patients; TsCHOPP [26] $n=16$ COPD patients, $n=24$ cystic fibrosis (CF) patients, $n=14$ idiopathic pulmonary fibrosis (IPF) patients, $n=11$ pulmonary hypertension (PHT) patients, $n=9$ other; ARIs [29] $n=15$ COPD patients, $\mathrm{n}=20$ CF patients, $\mathrm{n}=20$ other.

Indeed, the Turkish population has BMD values $\sim 1$ SD lower than the Swedish population [36]. The decreased BMD in the Turkish population may partly explain the lack of difference in prevalence of osteoporosis between COPD patients and healthy subjects [23].

\section{Correlates of osteoporosis in COPD}

To determine risk factors for osteoporosis, longitudinal (intervention) studies are preferred. To date, only two longitudinal studies that met the inclusion criteria have been identified [22, 33]. The other studies are cross-sectional (table 2). For this reason, interpretation of the results should be with caution as causality of the correlates (table 2) needs to be confirmed. Several studies found body composition measures (low BMI, low FFMI and \% of ideal body weight) to have a significant correlation with osteoporosis and/or $\operatorname{BMD}[12,20,25,28,30]$. In the general population, low body weight and/or low BMI have also been identified as risk factors for osteoporosis and incorporated in guidelines [8, 13]. The link between low body composition and osteoporosis or low BMD in COPD could be increased inflammation, decreased physical activity and/or other mechanisms leading to proteolysis [37-42]. Another explanation for more osteoporosis in patients with lower body composition measurements could be that bone formation is decreased because there is relatively low mechanical loading on these bones. Indeed, astronauts lose as much bone mass in a 1-month spaceflight as postmenopausal females in $1 \mathrm{yr}$ [43]. In addition, COPD patients have been shown to be physically inactive compared with age-matched healthy subjects [44].

MiNEO et al. [22] have found a significant correlation between an increase in BMD and an increase in BMI and FFM after lung volume reduction surgery. More longitudinal studies are 


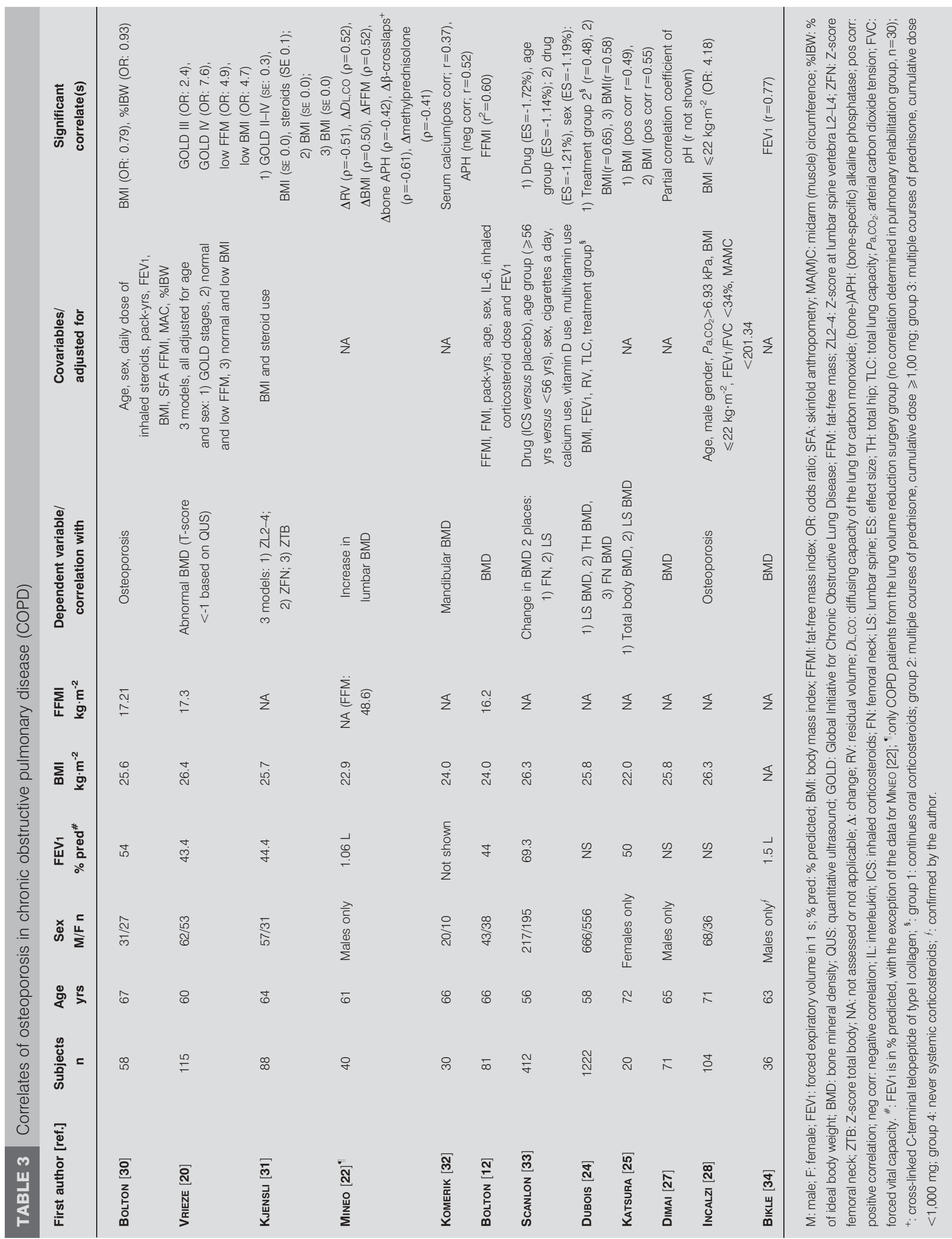


needed to investigate the influence of change in BMI and/or FFMI on change in BMD in COPD.

A higher GOLD stage and/or a lower FEV1 have been shown to be correlated with osteoporosis and/or a low BMD [20, 31, 34]. Also, in subjects without COPD, significant correlations between FEV1 and BMD have been found [45-47]. These relationships between lung function parameters and BMD are complex and not yet clear. Again, in COPD patients, systemic inflammation can be a key factor, as reduced lung function has been found to be associated with increased inflammatory markers, which is a risk factor for osteoporosis [48]. A strong relationship between serum 25-hydroxyvitamin D and pulmonary function parameters was found in patients from the third National Health and Nutrition Examination Survey [49]. This could be another link between lung function and BMD. It is also possible that there is no causal relationship between lung function and BMD. Perhaps reduced physical activity because of impaired lung function is the reason for reduced BMD [50]. More longitudinal studies are needed to investigate the possible causality between lung function and BMD.

Only SCANLON et al. [33] have found age $>56$ yrs and female sex to be independent correlates of osteoporosis in COPD. Indeed, in the general population higher, age and female sex are two of the most important risk factors for osteoporosis [8]. In COPD patients these risk factors may disappear after correction for other risk factors that are more important in COPD and less important in the general population. Other explanations could be limited sample size, cross-sectional design of most of the trials, inclusion of only males or only females and/or a selected age category. More large longitudinal trials are needed to investigate the influence of a higher age and/or female sex on BMD in COPD patients.

\section{Treatment of osteoporosis in COPD}

The pharmacological treatment of osteoporosis should consist of bisphosphonates in combination with calcium supplementation (in case of low dietary calcium intake) and with vitamin $\mathrm{D}$ supplements (in case of vitamin D deficiency) [8]. The protective effect of bisphosphonates has been found in multiple studies [51-54]. However, no studies were found investigating the drug treatment to prevent fractures in patients with osteoporotic COPD only. Two studies [55, 56] investigated alendronate in patients with asthma or COPD. Both studies treated the patients for $1 \mathrm{yr}$. SMITH et al. [56] found a significant improvement in T- and Z-scores for lumbar spine BMD, but not for BMD at the hip in the alendronate group. LAU et al. [55] found an increase in BMD in the alendronate group and a decrease in the placebo group, and these changes in BMD were significantly different between the two groups. In these studies, different eligibility criteria were used (males and females versus females only, patients with high fracture risk versus patients on inhaled corticosteroids). In addition, patient characteristics were different (67 versus 49 yrs of age, percentage asthma and COPD unknown versus majority asthma patients). The results of the two studies could not be pooled. These two studies may indicate that alendronate improves BMD in COPD patients.

MiRZAEI et al. [57] investigated the effect of rocaltrol in patients with a T-score $<-1$ and compared this with control patients.
However, patients and treating physicians were not blinded for treatment, because the patients were assigned to the control group if they had contra-indications for rocaltrol or if they were unwilling to use rocaltrol. Again, nothing can be concluded about the effect of rocaltrol in COPD patients only. Considering the methodological quality of the three described trials, only SMITH et al. [56] scored high on the Delphi scoring list (8 points) whereas the other two studies [55,57] scored very low (4 and 2 points, respectively;see online supplementary material, table E2). RCTs in COPD patients only and with a long-term follow-up are needed.

No studies were found that investigated the effect of lifestyle changes on BMD in COPD patients. However, in an RCT, lung transplantation patients who performed 6 months of exercise on a lumbar extensor machine significantly gained lumbar $\mathrm{BMD}$, in contrast to the control patients (also after lung transplantation without exercise) who lost lumbar BMD [58]. Another RCT compared the effect of alendronate plus mechanical loading to alendronate alone and to control patients (without alendronate and without mechanical loading) in lung transplant recipients [59]. Again, in control patients a significant decrease in BMD compared with baseline BMD was found after 8 months $(-14.1 \%)$. In patients treated with alendronate the BMD increased $(1.4 \%)$ and in the alendronate plus mechanical loading group the BMD increased even more $(10.8 \%)$. In contrast, in a 4 -yr RCT in middle-aged males regular aerobic exercise training had no significant effect on femoral BMD [60]. Intervention studies in COPD patients are needed to investigate the possible short- and long-term effects of progressive resistance training on BMD [61].

\section{Conclusions}

Prevalence of osteoporosis and osteopenia seems to be high in COPD patients. Correlates of osteoporosis in COPD are body composition measurements, measures of disease severity and corticosteroids. Although causality has not been proven, based on the current results it seems reasonable to advise (chest) physicians to screen for osteoporosis in COPD patients with a low BMI $\left(<21 \mathrm{~kg} \cdot \mathrm{m}^{-2}\right)$ and/or a low FFMI $\left(<16 \mathrm{~kg} \cdot \mathrm{m}^{-2}\right.$ in males and $<15 \mathrm{~kg} \cdot \mathrm{m}^{-2}$ in females). The effects of treatment of osteoporosis have not been investigated in patients with COPD only.

\section{Further areas where research is needed}

To determine risk factors of osteoporosis in COPD, more prospective studies are needed. Moreover, randomised (placebo-) controlled trials on the effects of pulmonary rehabilitation (including progressive resistance training and nutritional modulation [62]) and/or relevant drug treatment on BMD and fracture risk reduction are warranted in osteoporotic patients with COPD.

\section{STATEMENT OF INTEREST}

Statements of interest for E.F.M. Wouters and F.W.J.M. Smeenk can be found at www.erj.ersjournals.com $/ \mathrm{misc} /$ statements.dtl

\section{ACKNOWLEDGEMENTS}

We thank E.J. Martens (PhD, statistical advisor for the Dept of Education and Research, Catharina Hospital Eindhoven, Eindhoven, the Netherlands) for her statistical advice. We thank the following authors for providing additional information: L. Førli (Dept of Medicine, Rikshospitalet, University of Oslo, Oslo, Norway), C.E. 
Bolton (Dept of Respiratory Medicine, School of Medicine, Cardiff University, Cardiff, UK), F. Karadag (Dept of Chest Diseases, Adnan Menderes University School of Medicine, Aydin, Turkey), E.F. Dubois (Dept of Pulmonary Diseases, Reinier de Graaf Groep Delft and Voorburg, the Netherlands), R.M. Aris (Dept of Medicine, Surgery and Transplant, The University of North Carolina, at Chapel Hill, NC, USA), N.R. Jørgensen (Dept of Clinical Biochemistry, Copenhagen University Hospital Hvidovre, Hvidovre, Denmark) and D.D. Bikle (Endocrine Unit, VA Medical Center, San Francisco, CA, USA).

\section{REFERENCES}

1 Rabe KF, Hurd S, Anzueto A, et al. Global strategy for the diagnosis, management, and prevention of chronic obstructive pulmonary disease: GOLD executive summary. Am J Respir Crit Care Med 2007; 176: 532-555.

2 Agusti AG. Systemic effects of chronic obstructive pulmonary disease. Proc Am Thorac Soc 2005; 2: 367-370.

3 Sabit R, Bolton CE, Edwards PH, et al. Arterial stiffness and osteoporosis in chronic obstructive pulmonary disease. Am J Respir Crit Care Med 2007; 175: 1259-1265.

4 Schols AM, Broekhuizen R, Weling-Scheepers CA, et al. Body composition and mortality in chronic obstructive pulmonary disease. Am J Clin Nutr 2005; 82: 53-59.

5 Wouters EF. Introduction: systemic effects in chronic obstructive pulmonary disease. Eur Respir J Suppl 2003; 46: 1s.

6 Holguin F, Folch E, Redd SC, et al. Comorbidity and mortality in COPD-related hospitalizations in the United States, 1979 to 2001. Chest 2005; 128: 2005-2011.

7 Biskobing DM. COPD and osteoporosis. Chest 2002; 121: 609-620.

8 WHO Scientific Group on the Prevention and Management of Osteoporosis. Prevention and Management of Osteoporosis: report of a WHO scientific group. http://whqlibdoc.who.int/trs/ WHO_TRS_921.pdf. Date last accessed: December 2, 2008.

9 Abe E, Sun L, Mechanick J, et al. Bone loss in thyroid disease: role of low TSH and high thyroid hormone. Ann N Y Acad Sci 2007; 1116: 383-391.

10 Compston JE. Risk factors for osteoporosis. Clin Endocrinol (Oxf) 1992; 36: 223-224.

11 Lumachi F, Camozzi V, Ermani M, et al. Bone mineral density improvement after successful parathyroidectomy in pre- and postmenopausal women with primary hyperparathyroidism: a prospective study. Ann N Y Acad Sci 2007; 1117: 357-361.

12 Bolton CE, Ionescu AA, Shiels KM, et al. Associated loss of fat-free mass and bone mineral density in chronic obstructive pulmonary disease. Am J Respir Crit Care Med 2004; 170: 1286-1293.

13 Shepherd AJ, Cass AR, Carlson CA, et al. Development and internal validation of the male osteoporosis risk estimation score. Ann Fam Med 2007; 5: 540-546.

14 Leech JA, Dulberg C, Kellie S, et al. Relationship of lung function to severity of osteoporosis in women. Am Rev Respir Dis 1990; 141: 68-71.

15 Bapoje SR, Whitaker JF, Schulz T, et al. Preoperative evaluation of the patient with pulmonary disease. Chest 2007; 132: 1637-1645.

16 Smetana GW. Preoperative pulmonary evaluation. N Engl J Med 1999; 340: 937-944.

17 Trayner E Jr, Celli BR. Postoperative pulmonary complications. Med Clin North Am 2001; 85: 1129-1139.

18 Verhagen AP, de Vet HC, de Bie RA, et al. The Delphi list: a criteria list for quality assessment of randomized clinical trials for conducting systematic reviews developed by Delphi consensus. J Clin Epidemiol 1998; 51: 1235-1241.

19 Forli L, Mellbye OJ, Halse J, et al. Cytokines, bone turnover markers and weight change in candidates for lung transplantation. Pulm Pharmacol Ther 2008; 21: 188-195.
20 Vrieze A, de Greef MH, Wijkstra PJ, et al. Low bone mineral density in COPD patients related to worse lung function, low weight and decreased fat-free mass. Osteoporos Int 2007; 18: 1197-1202.

21 Jørgensen NR, Schwarz P, Holme I, et al. The prevalence of osteoporosis in patients with chronic obstructive pulmonary disease: a cross sectional study. Respir Med 2007; 101: 177-185.

22 Mineo TC, Ambrogi V, Mineo D, et al. Bone mineral density improvement after lung volume reduction surgery for severe emphysema. Chest 2005; 127: 1960-1966.

23 Karadag F, Cildag O, Yurekli Y, et al. Should COPD patients be routinely evaluated for bone mineral density? J Bone Miner Metab 2003; 21: 242-246.

24 Dubois EF, Roder E, Dekhuijzen PN, et al. Dual energy X-ray absorptiometry outcomes in male COPD patients after treatment with different glucocorticoid regimens. Chest 2002; 121: 1456-1463.

25 Katsura H, Kida K. A comparison of bone mineral density in elderly female patients with COPD and bronchial asthma. Chest 2002; 122: 1949-1955.

26 Tschopp O, Boehler A, Speich R, et al. Osteoporosis before lung transplantation: association with low body mass index, but not with underlying disease. Am J Transplant 2002; 2: 167-172.

27 Dimai HP, Domej W, Leb G, et al. Bone loss in patients with untreated chronic obstructive pulmonary disease is mediated by an increase in bone resorption associated with hypercapnia. J Bone Miner Res 2001; 16: 2132-2141.

28 Incalzi RA, Caradonna P, Ranieri $\mathrm{P}$, et al. Correlates of osteoporosis in chronic obstructive pulmonary disease. Respir Med 2000; 94: 1079-1084.

29 Aris RM, Neuringer IP, Weiner MA, et al. Severe osteoporosis before and after lung transplantation. Chest 1996; 109: 1176-1183.

30 Bolton CE, Cannings-John R, Edwards PH, et al. What community measurements can be used to predict bone disease in patients with COPD? Respir Med 2008; 102: 651-657.

31 Kjensli A, Mowinckel P, Ryg MS, et al. Low bone mineral density is related to severity of chronic obstructive pulmonary disease. Bone 2007; 40: 493-497.

32 Komerik N, Akkaya A, Yildiz M, et al. Oral health in patients on inhaled corticosteroid treatment. Oral Dis 2005; 11: 303-308.

33 Scanlon PD, Connett JE, Wise RA, et al. Loss of bone density with inhaled triamcinolone in Lung Health Study II. Am J Respir Crit Care Med 2004; 170: 1302-1309.

34 Bikle DD, Halloran B, Fong L, et al. Elevated 1,25-dihydroxyvitamin $\mathrm{D}$ levels in patients with chronic obstructive pulmonary disease treated with prednisone. J Clin Endocrinol Metab 1993; 76: 456-461.

35 Szymanski P, Mosiewicz J, Myslinski W, et al. The influence of chronic obstructive pulmonary disease on the occurrence rate and intensification of osteoporosis. Ann Univ Mariae Curie Sklodowska [Med] 2002; 57: 187-195.

36 Tuzun S, Akarirmak U, Uludag M, et al. Is BMD sufficient to explain different fracture rates in Sweden and Turkey? J Clin Densitom 2007; 10: 285-288.

37 Balasubramanian VP, Varkey B. Chronic obstructive pulmonary disease: effects beyond the lungs. Curr Opin Pulm Med 2006; 12: 106-112.

38 Eid AA, Ionescu AA, Nixon LS, et al. Inflammatory response and body composition in chronic obstructive pulmonary disease. Am J Respir Crit Care Med 2001; 164: 1414-1418.

39 Kardos P, Keenan J. Tackling COPD: a multicomponent disease driven by inflammation. MedGenMed 2006; 8: 54.

40 Roth M. Pathogenesis of COPD. Part III. Inflammation in COPD. Int J Tuberc Lung Dis 2008; 12: 375-380.

41 Wouters EF. Local and systemic inflammation in chronic obstructive pulmonary disease. Proc Am Thorac Soc 2005; 2: 26-33.

42 Yawn BP, Kaplan A. Co-morbidities in people with COPD: a result of multiple diseases, or multiple manifestations of smoking and reactive inflammation? Prim Care Respir J 2008; 17: 199-205. 
43 Cavanagh PR, Licata AA, Rice AJ. Exercise and pharmacological countermeasures for bone loss during long-duration space flight. Gravit Space Biol Bull 2005; 18: 39-58.

44 Van Vliet M, Spruit MA, Verleden G, et al. Hypogonadism, quadriceps weakness, and exercise intolerance in chronic obstructive pulmonary disease. Am J Respir Crit Care Med 2005; 172: 1105-1111.

45 Choi JW, Pai SH. Association between respiratory function and osteoporosis in pre- and postmenopausal women. Maturitas 2004; 48: 253-258.

46 Lekamwasam S, Trivedi DP, Khaw KT. An association between respiratory function and bone mineral density in women from the general community: a cross sectional study. Osteoporos Int 2002; 13: 710-715.

47 Lekamwasam S, Trivedi DP, Khaw KT. An association between respiratory function and hip bone mineral density in older men: a cross-sectional study. Osteoporos Int 2005; 16: 204-207.

48 Gan WQ, Man SF, Senthilselvan A, et al. Association between chronic obstructive pulmonary disease and systemic inflammation: a systematic review and a meta-analysis. Thorax 2004; 59: 574-580.

49 Black PN, Scragg R. Relationship between serum 25-hydroxyvitamin $\mathrm{d}$ and pulmonary function in the third national health and nutrition examination survey. Chest 2005; 128: 3792-3798.

50 Watz H, Waschki B, Boehme C, et al. Extrapulmonary effects of chronic obstructive pulmonary disease on physical activity: a cross-sectional study. Am J Respir Crit Care Med 2008; 177: 743-751.

51 Black DM, Schwartz AV, Ensrud KE, et al. Effects of continuing or stopping alendronate after 5 years of treatment: the Fracture Intervention Trial Long-term Extension (FLEX): a randomized trial. JAMA 2006; 296: 2927-2938.

52 Bone HG, Hosking D, Devogelaer JP, et al. Ten years' experience with alendronate for osteoporosis in postmenopausal women. $N$ Engl J Med 2004; 350: 1189-1199.
53 Fogelman I, Ribot C, Smith R, et al. Risedronate reverses bone loss in postmenopausal women with low bone mass: results from a multinational, double-blind, placebo-controlled trial. BMD-MN Study Group. J Clin Endocrinol Metab 2000; 85: 1895-1900.

54 McClung MR, Geusens P, Miller PD, et al. Effect of risedronate on the risk of hip fracture in elderly women. Hip Intervention Program Study Group. N Engl J Med 2001; 344: 333-340.

55 Lau EM, Woo J, Chan YH, et al. Alendronate for the prevention of bone loss in patients on inhaled steroid therapy. Bone 2001; 29: 506-510.

56 Smith BJ, Laslett LL, Pile KD, et al. Randomized controlled trial of alendronate in airways disease and low bone mineral density. Chron Respir Dis 2004; 1: 131-137.

57 Mirzaei S, Zajicek HK, Knoll P, et al. Effect of rocaltrol on bone mass in patients with pulmonary disease treated with corticosteroids. J Asthma 2003; 40: 251-255.

58 Mitchell MJ, Baz MA, Fulton MN, et al. Resistance training prevents vertebral osteoporosis in lung transplant recipients. Transplantation 2003; 76: 557-562.

59 Braith RW, Conner JA, Fulton MN, et al. Comparison of alendronate $v s$ alendronate plus mechanical loading as prophylaxis for osteoporosis in lung transplant recipients: a pilot study. J Heart Lung Transplant 2007; 26: 132-137.

60 Huuskonen J, Vaisanen SB, Kroger H, et al. Regular physical exercise and bone mineral density: a four-year controlled randomized trial in middle-aged men. The DNASCO study. Osteoporos Int 2001; 12: 349-355.

61 Spruit MA, Gosselink R, Troosters $\mathrm{T}$, et al. Resistance versus endurance training in patients with COPD and peripheral muscle weakness. Eur Respir J 2002; 19: 1072-1078.

62 Spruit MA, Wouters EF. New modalities of pulmonary rehabilitation in patients with chronic obstructive pulmonary disease. Sports Med 2007; 37: 501-518. 